\title{
On the diversity in design for different bending fretting fatigue mechanism
}

\author{
Quazi Md. Zobaer Shah ${ }^{1,2}$ (D). Md. Asaduzzaman Chowdhury ${ }^{3} \cdot$ Md. Arefin Kowser ${ }^{4}$
}

(C) Springer Nature Switzerland AG 2019

\begin{abstract}
Fretting fatigue has emerged as the center of interest for research in recent decades due to its high importance in real application field. Despite this advancement, comparatively few experiments as well as studies have been accomplished on bending fretting fatigue. Researchers either developed new test rigs or accepted a conventional concept since there exists no specific, standalone and standard test rig. However, as it is difficult to compare each work with others, the increasing number of test rigs are not suitable to ensure the justified results under conditional circumstance. This article classified the existing bending fretting fatigue test rigs depending on the variable parameters like fretting and loading actions. It can be mentioned that reciprocating fretting fatigue test rigs have more diversities as compared to rotary fretting fatigue test rigs due to the advantages of variable loading values, displacement controlling, fretting damage pre-determination and other desirable purposes. This article might be useful as a state of art for future contributions of the modern technology in industrial applications.
\end{abstract}

Keywords Bending fretting fatigue $\cdot$ Test rigs $\cdot$ Reciprocating BFFTR $\cdot$ Rotary BFFTR

\section{Introduction}

Fretting is characterized as the continuous but slow erode of something by friction of contact. It is a type of surface deterioration process occurring in the adjacent territory of two bodies under load and ignorable dislocation by some forces [1]. It presents surface deterioration [2-5]. In spite of numerous researches on fretting fatigue, only a few experiments have been counted on bending fretting fatigue that occurs within two connected bodies trying to sliding/rolling over that surface. It was proved by Hattori [6] that the fretting fatigue strength decreased is less than one-third of simple fatigue strength. If the relative motion is dominated by cyclic bending force, it is then termed as bending fretting fatigue. The common applications are in contact like bolts, railway axles, nuclear reactors, wheel-sets etc. [7-9]. Some researches established the relationship between plain fatigues and dislocated structures [10-12] when others emphasized on fretting [13]. Hills and Nowell derived fretting fatigue mechanism and classified test rigs based on the contact geometry [7]. De Pauw et al. [14] reviewed and presented a diversity of rigs in 2011 . Those were classified as full and coupon scale testing setups where coupon scale had much varieties and slip control advantage Peng and Zhu [15-17] used a servo-hydraulic clamped rig for bending fretting of various materials. Ebara and Fujimura [8] experimented on shoe-bolt tightened bending fretting test rig. Kubota [18] studied and showed the $\mathrm{H}_{2}$ effect on bending fretting fatigue using bar-spring tightened test rig. Zalnezhad and Ahmed designed a new test rig for rotary bending fretting fatigue [19, 20], Song [21]

$\triangle$ Quazi Md.Zobaer Shah, qmzshah@gmail.com; Md. Asaduzzaman Chowdhury, asadzmn2014@yahoo.com; Md. Arefin Kowser, nadimduet@yahoo.com | ${ }^{1}$ Healthcare Pharmaceuticals Ltd, Dhaka, Bangladesh. ${ }^{2}$ Dhaka University of Engineering and Technology, 419/8, Shah Monjil, West Bhurulia, Gazipur 1707, Bangladesh. ${ }^{3}$ Department of Industrial Production and Engineering, Dhaka University of Engineering and Technology, 419/8, Shah Monjil, West Bhurulia, Gazipur 1707, Bangladesh. ${ }^{4}$ Department of Materials Science and Engineering, Dhaka University of Engineering and Technology, 419/8, Shah Monjil, West Bhurulia, Gazipur 1707, Bangladesh.

SN Applied Sciences (2019) 1:1067 | https://doi.org/10.1007/s42452-019-1107-y 
conveyed comparatively complex setup for justifying rotary bending fretting on railway axle. Recent researches are being carried out on rotating bending $[22,23]$. Van Paepegem et al. [24] used bending fatigue rig for composite materials where fretting action can be considered between sample and fixed joint. Notable reviews and experiments were carried out on wear, fatigue [25-38] as well as fretting fatigue [23,39-49] However, relatively less on bending accelerated fretting fatigue $[22,50-52]$. Considering all above mentioned parameters with conditions, some perfect attributes [53] of fretting fatigue test rigs (FFTR) must have Versatility to various dimensions and stiffness of the samples and fretting pads; Possibility to perform different states of load (constant or alternating load); Scope to create fretting fatigue mechanism by recording the information from various tried materials that could be applied to different model to foresee the fatigue life; Accessibility to gauge fretting stresses and strains; Minimal cost of setup to perform a few tests at the same time; Flexibility of load recurrence.

The aim of the present article is to review and demonstrate the most recent bending fretting fatigue test rigs with different concepts. This article may pave the innovative ways for imagination to design and fabricate new types of test rigs. Future researchers may find this article helpful for evaluating the properties of bending fretting fatigue of different materials in the concerned industrial applications.

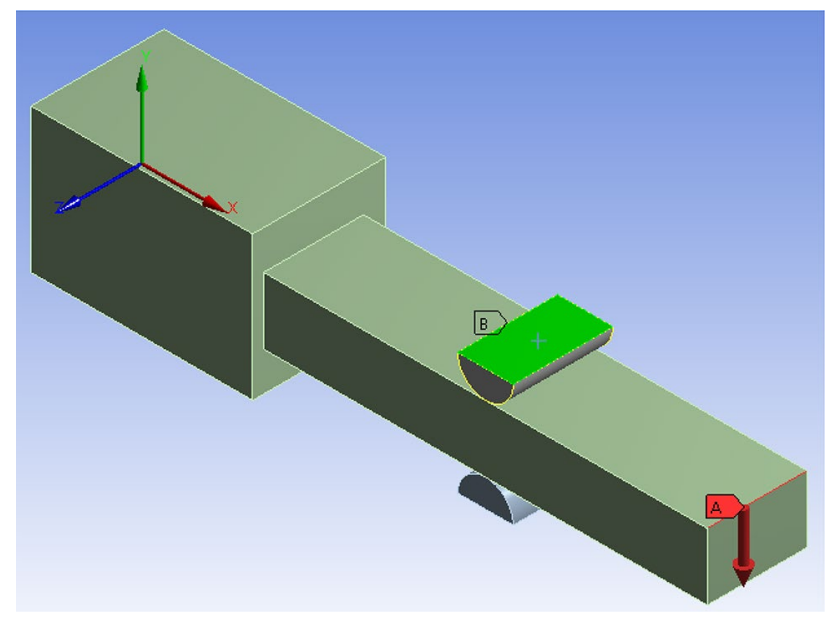

Fig. 1 Bending fretting fatigue

\section{Recent bending fretting fatigue test rigs}

Figure 1 shows a simple bending fretting fatigue setup. Here $A$ denotes loading at the edge of the sample. $B$ shows fretting pads at the middle portion of the sample. As loading is applied, body bends and fretting action occurs between the sample and pad. As loading reciprocates along $\mathrm{Y}-\mathrm{Y}$ axis, it is thus termed as reciprocating bending fretting fatigue. If specimen rotates along the axis through center while bending, then the system is called rotating bending fretting fatigue.

\subsection{RBFFTR (reciprocating bending type fretting fatigue test rig)}

\subsubsection{Bar-spring fastened double bending fretting fatigue test rig [18]}

Figure 2 presents a test rig used in [18]. A pair of friction pads were tightened over the top and back areas of tests specimen. Pressure of contact was adjusted for keeping constant normal pressure of $100 \mathrm{MPa}$. Tightening the system implied the load of contact. In order to balance decrease in contact load by increasing fretting wear, contact load was kept steady by negligible wear. At the final stage, contact load decreased by $5 \%$ of the beginning value. Fatigue loading was plane bending type where stress ratio and frequency were 1 and $18.7 \mathrm{~Hz}$ respectively. Figure 2 shows the test specimen size and shape under contact of pads. Specimen was square bar type with glued strain gage to the flat contact pad. Hydrogen gas and air was used as test environment condition. By passing nitrogen gas, chamber was flushed to experiment fretting fatigue.

\subsubsection{Shoe-bolt fastened bending fretting fatigue test setup [8]}

Figure 3 shows fretting fatigue test setup for Ti-6Al-4V plate of $10 \mathrm{~mm}$ thickness with bolt tightened shoe on both side. Dimensions of fretting shoe and bolt are shown in Fig. 4 that were produced from Ti-6Al-4V and SCM4 steel, respectively. Contact pressure acts on point $S$ in Fig. 5. The contact pressure is obtained from the strain calculated by a strain gage settled at the bolt center. The maximum load $P_{\max }$ is mentioned by $P_{\max }=0.418(P E / I R)^{1 / 2}$ where, $P=$ load per unit thickness (MPa), $E=$ Young's modulus ( $\mathrm{MPa})$, $\mathrm{R}=$ radius of the shoe and $\mathrm{I}=$ the contact length. $\mathrm{A}$ regular fatigue testing rig was used. Fretting fatigue setup is shown in Fig. 3. 


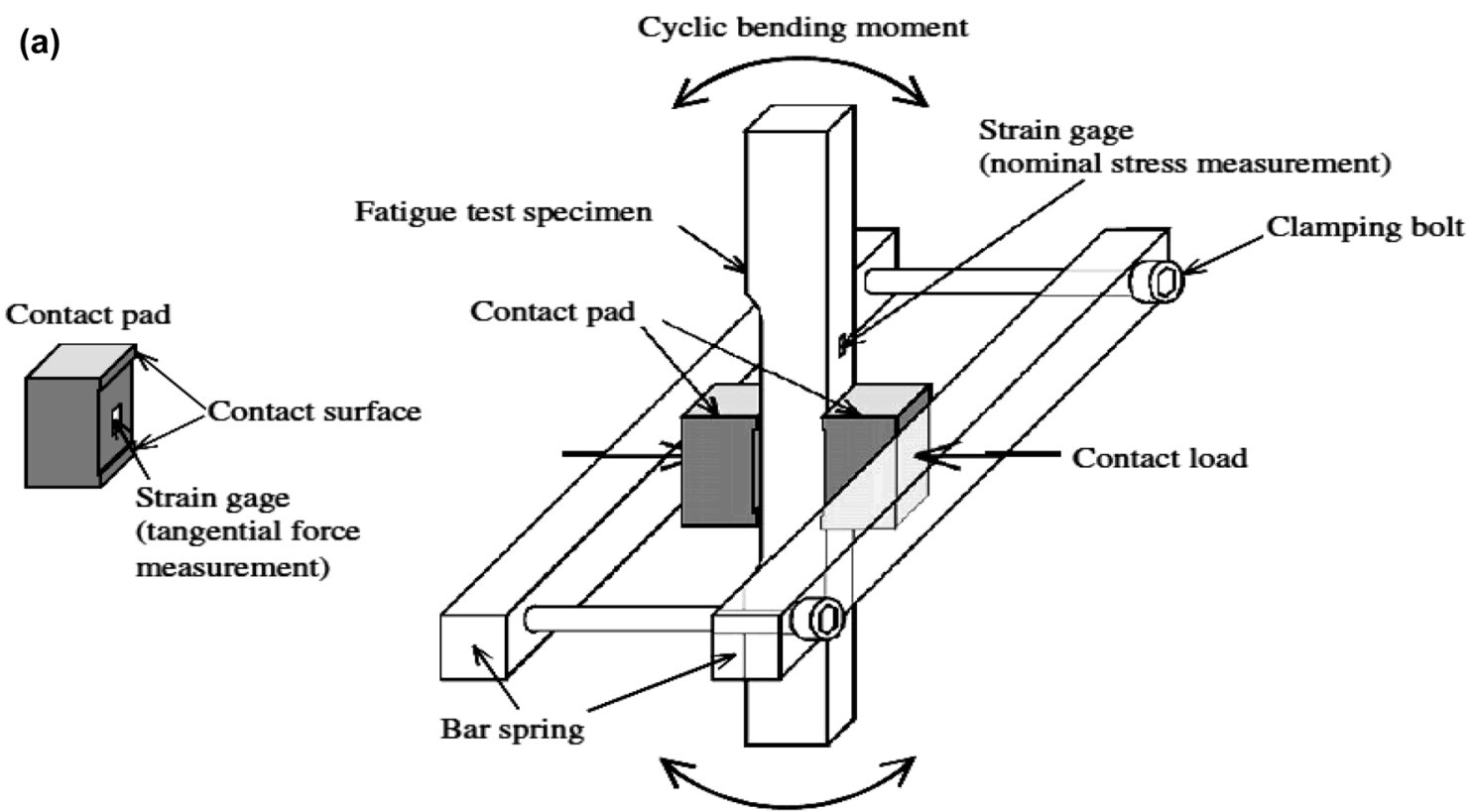

(b)
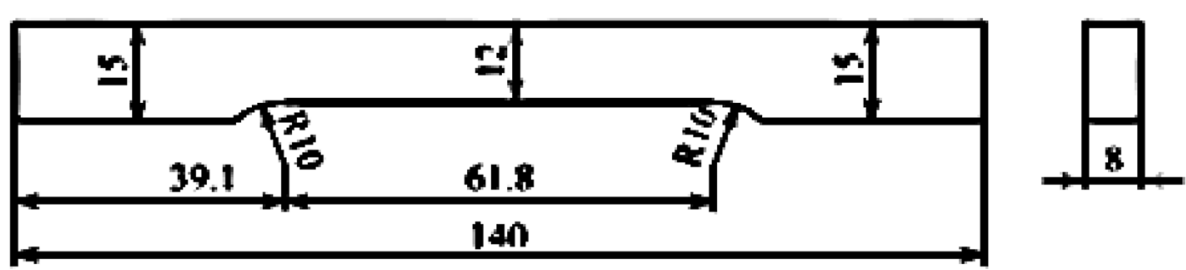

b
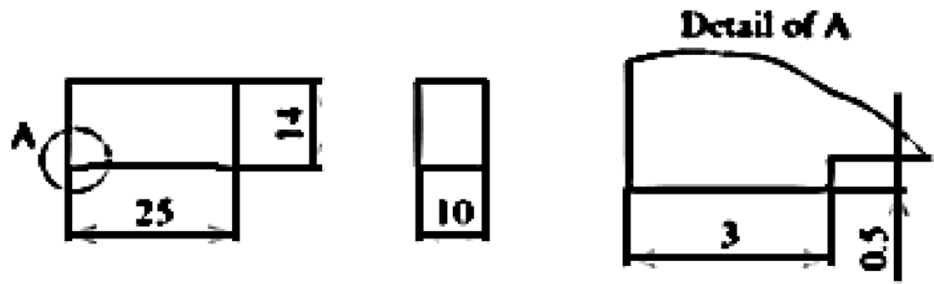

Fig. 2 Fretting fatigue test setup, Specification of the sample and contact pad (dimensions are in $\mathbf{m m}$ ): $\mathbf{a}$ fatigue test specimen and $\mathbf{b}$ bridge type contact pad [18]. (Permission granted for use through Copyright Clearance Center's RightsLink)

\subsubsection{Hinged loaded displacement controlled bending fretting fatigue test rig [53]}

This is a fatigue testing machine for composite materials. Here, fretting fatigue action can be considered at the bolted bars tightened together with the beam especially harder than composites. There exists three modules as followings:

- First/main/control module: it creates a sinusoidal loading;

- Second/loading module: it changes loading functions;
- Third/information module: it calculates the load or stress as well as examines the qualities.

\subsubsection{The primary (or control) module [53]}

Plane bending fatigue testing setup is shown in Fig. 6 . A three phase motor (1) and inverter (2) rotates pulley by a belt (3) connected with a shaft (4) with transmission proportion equivalent to one. Optical tachometer checks the transmission proportion. A cam (5) permits to invert rotation in a simple symmetric-oscillating motion of transmitting rod (6). The sample is tied to a 


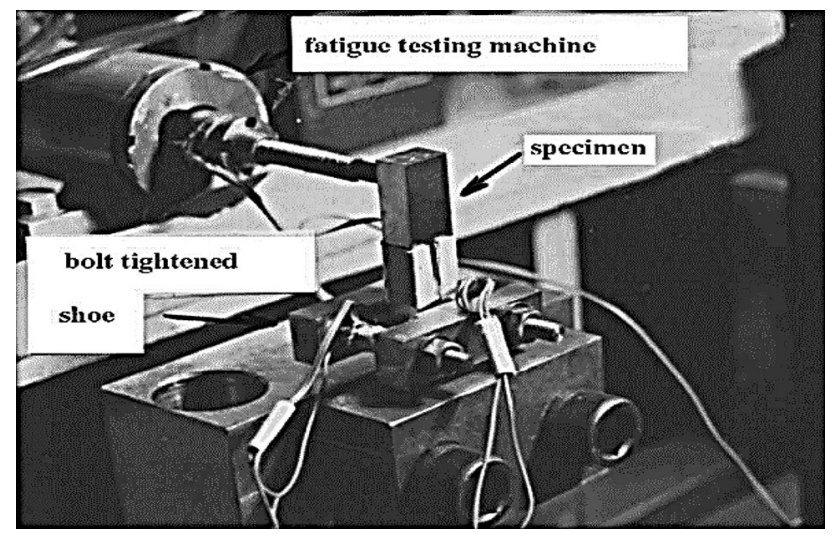

Fig. 3 Fretting fatigue testing view [8]. (Permission granted for use (Figs. 3, 4, 5) through Copyright Clearance Center's RightsLink)

bar tightened with a stand (8). Rotating disc (Q) center to hinge point $(P)$ distance controls the stress value. Eccentricity of disc and variable length of connecting rod alters the loading type. Figure 7 shows the schematic drawing.

\subsubsection{The second module [53]}

Figure 8 shows second module that permits to change the connecting rod's length and to change some geometric value. Rod expansion can be adjusted to micro level to modify the force value as well as stress type (alternating or constant). Sample's deflection can be

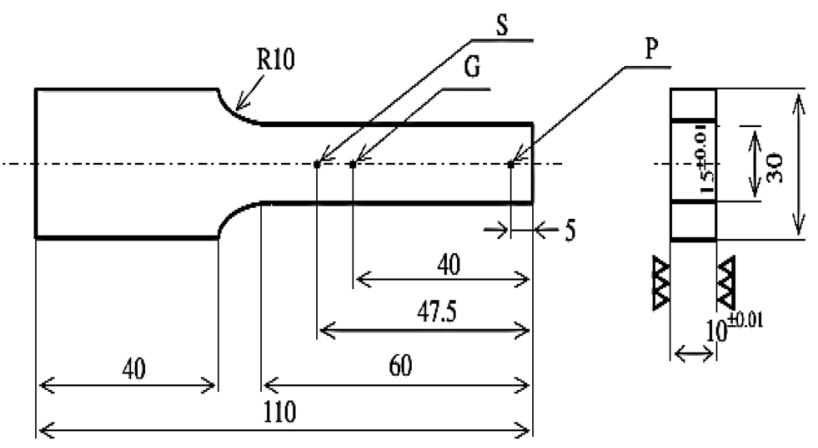

Fig. 5 Fretting fatigue sample (dimensions are in $\mathrm{mm}$ ) [8]. $P$ loading point, $G$ strain measuring point and $S$ contact point with shoe

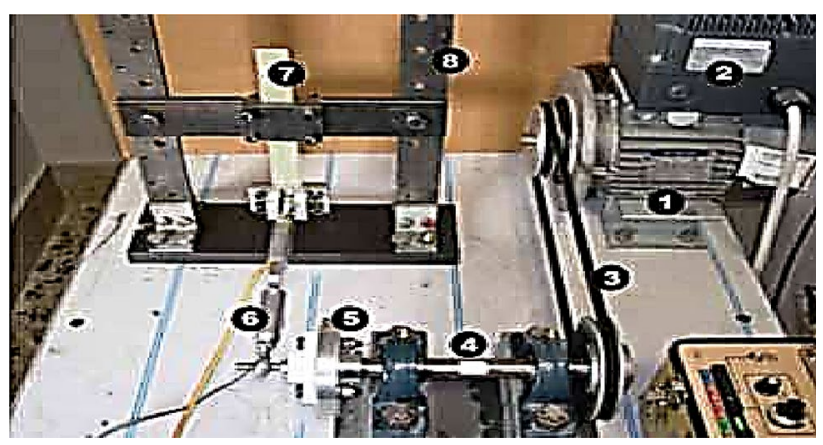

Fig. 6 Materials testing machine [53]. (Used under Creative Commons Attribution-Noncommercial- ShareAlike-3.0 License)

altered from zero to highest value. The crossbar Sliding enables samples of different lengths to be tested under maximum force.
Fig. 4 Fretting shoe and bolt (dimensions are in $\mathrm{mm}$ ) [8]
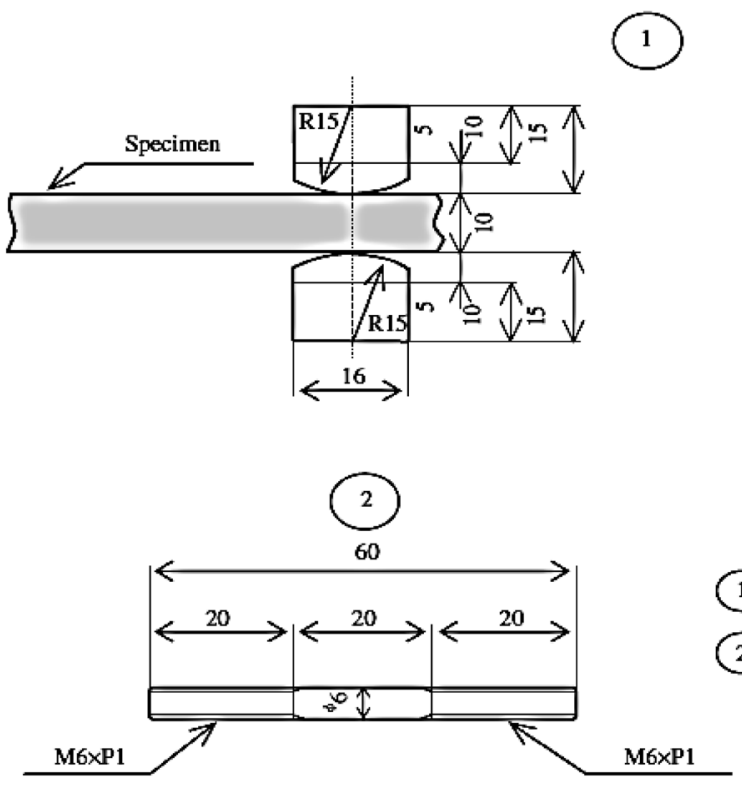

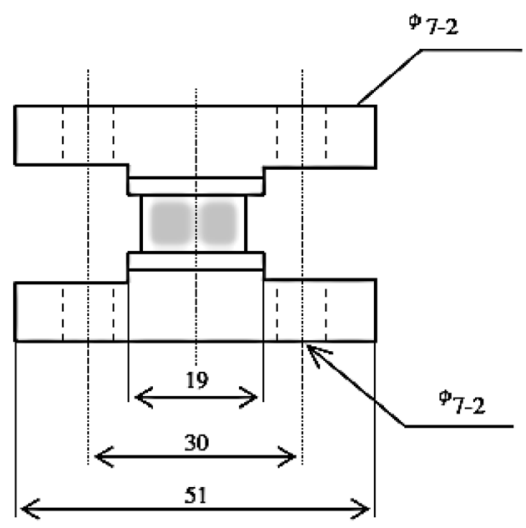

(1) Fretting shoe

(2) Bolt 


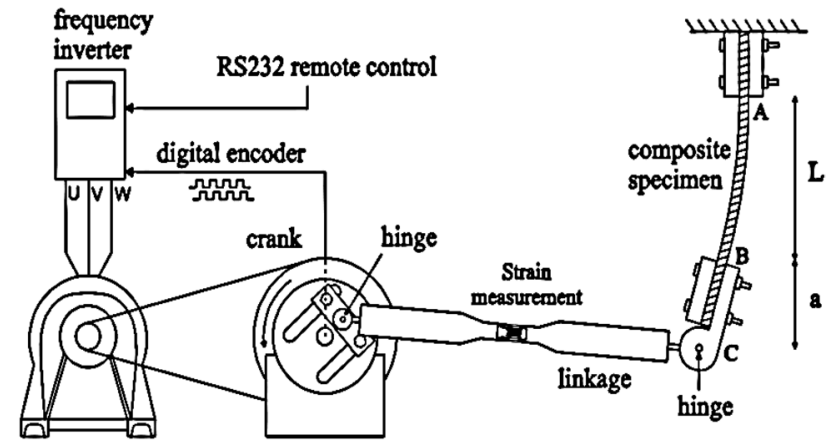

Fig. 7 Schematic diagram of materials testing machine [53]. (Used under Creative Commons Attribution-Noncommercial- ShareAlike-3.0 License)

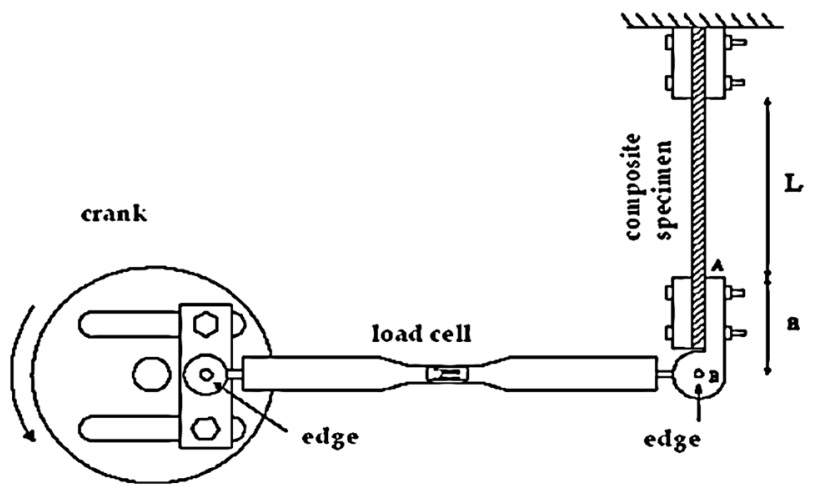

Fig. 8 Schematic Diagram [53]. (Used under Creative Commons Attribution-Noncommercial-ShareAlike-3.0 License

\subsubsection{The third (or data acquisition) module [53]}

Loads are checked and registered by a committed procurement framework amid the trial tests. The entire framework comprises of a strain sensor (load cell), a strain pointer, an advanced simple connector and a PC as shown in Fig. 9. Special software programming, designed and developed in LabView room, permits to save and show the estimations of variety of stiffness of the composite or the bonded joint, in this way getting progressively the damage versus the time or cycles number. The abatement in stiffness is calculated through the stress till sample failure, working with steady sufficiency strain. Additionally it is conceivable to utilize any paradigm of fatigue life of composite materials.

\subsubsection{Bending fretting fatigue test rig of servo hydraulic clamped type [15]}

The test rig appeared in Fig. 10 shows a servo hydraulic system for testing. A tightening screw was used to imply the normal force on the sample at A-B line and A point shown in Fig. 11 amid the tests. Both setups of line and point contacts for fatigue can be evaluated as appeared. A small load cell was used to calculate the normal load as shown in Fig. 11. At the site of C-D line bending force was applied as shown in Fig. 11 for all tests. Hertzian contact theory was used to calculate normal stresses and loads [54].

\subsection{Rotary bending type fretting fatigue test rig}

\subsubsection{General/light purpose (bridge type pads) RoBFFTR [20]}

In this research work [20], fretting fatigue conceptualized rotating bending machine was used. Figures 12 and 13 presents the perspective drawing. It consists a platform (1), an engine (2), couplings (3) with shaft (4), transmission direction (5), chuck (6), pulley (7) and a load cell (8) for
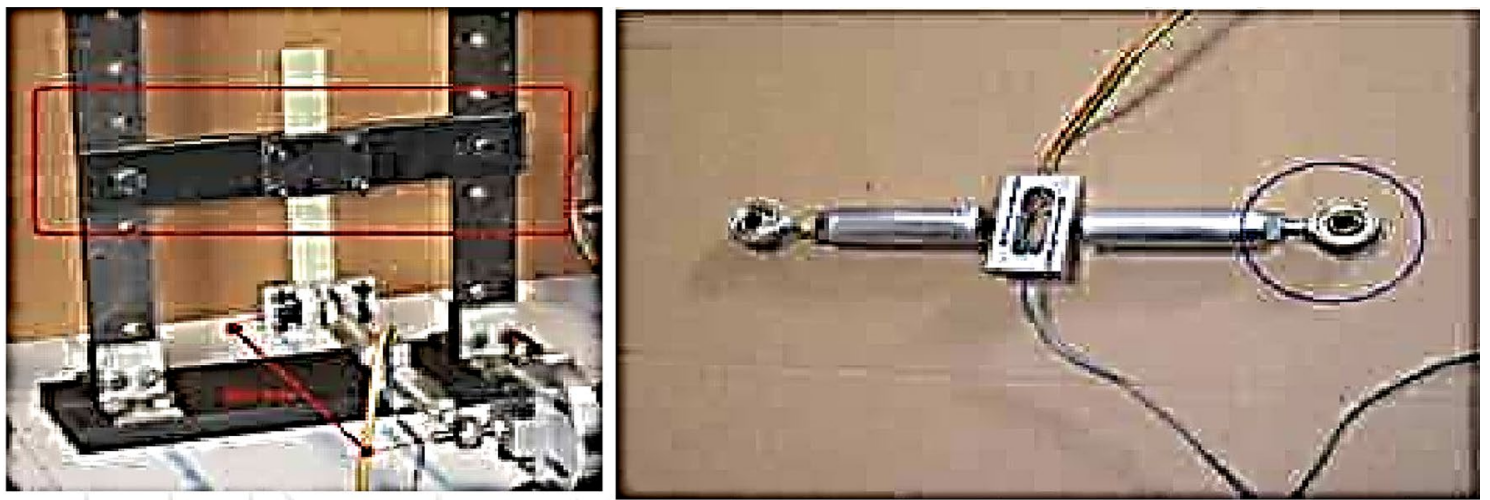

Fig. 9 Testing mechanism for horizontal bar (left) and joint (right) [53]. (Used under Creative Commons Attribution-Noncommercial- ShareAlike-3.0 License) 

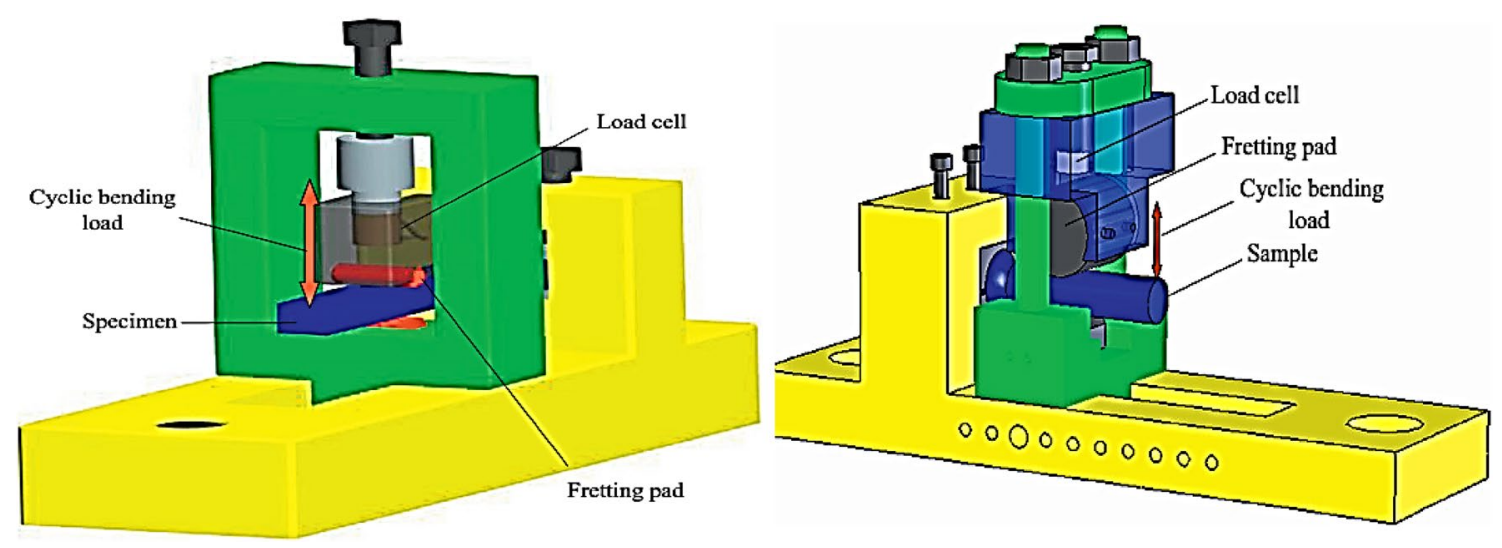

Fig. 10 Two contact configurations [15]. (Permission granted for use through Copyright Clearance Center's RightsLink)
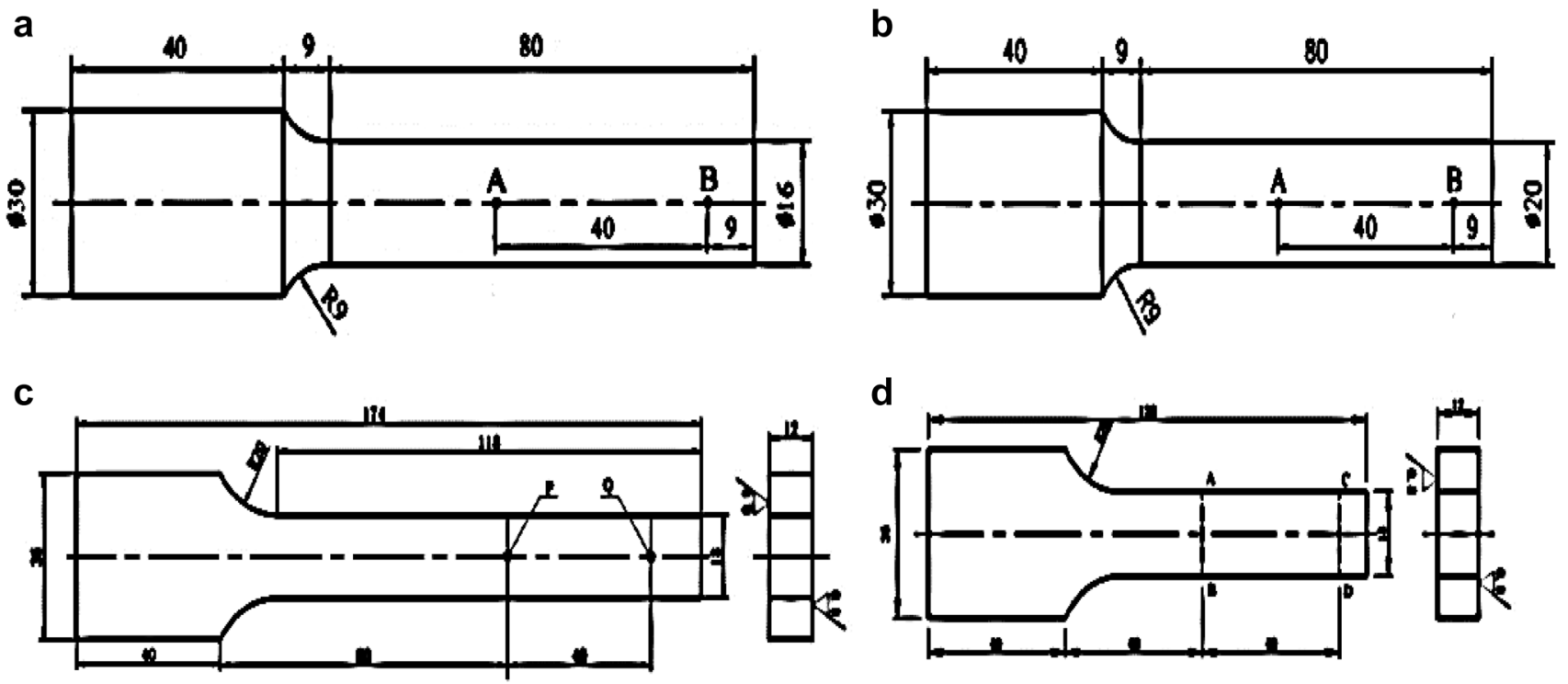

Fig. 11 Specimen geometry for fatigue test of different materials under point (b) and line (d) loading [15]. (Permission granted for use through Copyright Clearance Center's RightsLink)

force measurement. Spring pair with support applied the force. FEM tool, ABAQUS was used for validating experimental results by adaptive mesh refinement. The fatigue sample possessed Young's modulus of $72 \mathrm{GPa}$ and The Poisson's ratio equivalent to 0.3 .

The bearing with pads were rigid material. Face to face little sliding contact was assumed between the pads and sample. Coefficient of Friction (COF) of 0.3 was relegated to connected pads and sample. Figure $14 \mathrm{~d}$ additionally demonstrates that the most extreme distribution point.

\subsubsection{Press-fitted joint/thick disc type pads type RoBFFTR} [3]

The device used in this research [28] is appeared in Fig. 15 (left). There is a pole/shaft inserted into a hole by cooling the shaft and heating the hole. $20 \mathrm{~kg}$ load was implied as bending load for free movement. See Fig. 15 (Right). A motor was used to rotate the fitting as shown in Fig. 18 by method for a cinching grasp. 


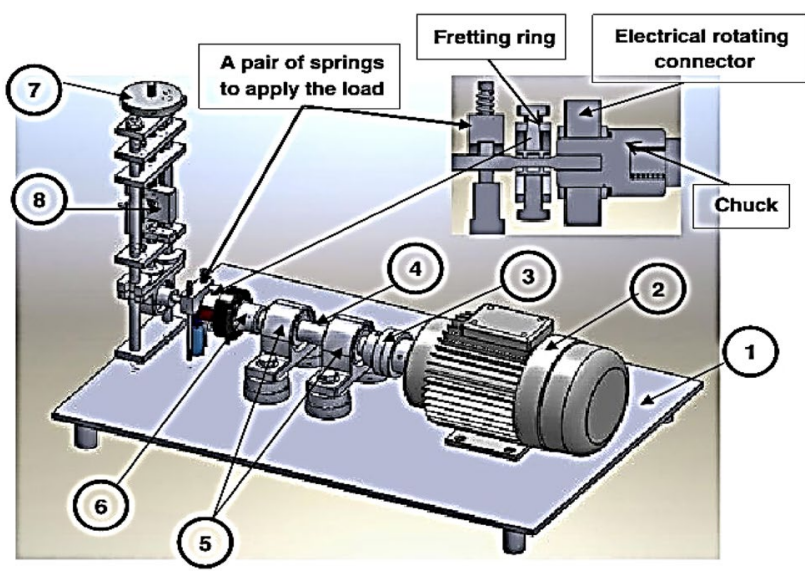

Fig. 12 Schematic diagram of testing setup [20]. (Permission granted for use through Copyright Clearance Center's RightsLink)

\subsubsection{Medium purpose (Moore fatigue) RoBFFTR [55]}

Moore fatigue testing machine supplied Bending fatigue mechanism. In this setup, samples are subjected to pure bending and hence to a totally reversed bending stresses. Upper side of Moore sample is without shear stresses. While turning, sample faces tension and compression simultaneously. A proven ring with strain gage was assembled to apply constant load as well as fretting load that implied by the tightening of screw and spring. Nonetheless, the yield of the Wheatstone bridge was calculated. This methodology was rehashed for various spring powers and the variety of the spring power versus the strain gage yield was acquired. This variety is known as the alignment curve of the proven ring. Furthermore, this proven ring was utilized for delivering the contact load and measuring its magnitude as a load cell. By adjusting the screws and utilizing the alignment curve, the required level of contact load can be accomplished. Fretting fatigue tests were operated at a frequency of $30 \mathrm{~Hz}$. The constant contact fretting force was $1300 \mathrm{~N}$ throughout the experiment. S-N graph was obtained under variable bending stresses for with and without fretting conditions. It was found that fretting along with characteristics length, conforming and non-conforming contact reduces the fatigue life significantly. The total system is shown Figs. 16, 17, 18.

\subsubsection{Railway axle (complex/specific) purpose RoBFFTR} [21]

A rotatory setup was designed, as in Fig. 19. It shows wheel axle (15) pinchcock (16) for motion transfer. Wheel
Fig. 13 Bending fatigue test machine [20]. (Permission granted for use through Copyright Clearance Center's RightsLink)

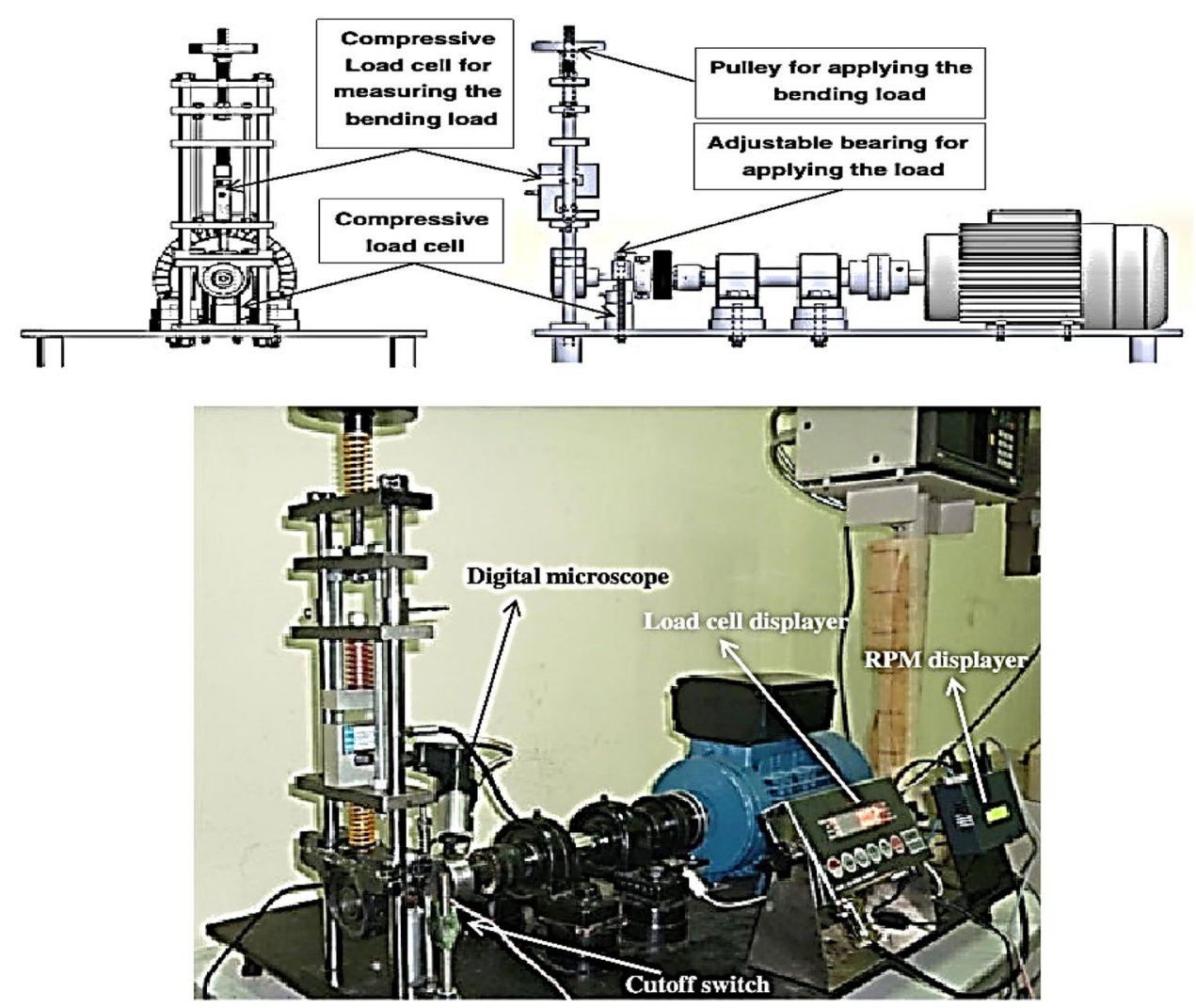

SN Applied Sciences A SPRINGER NATURE journal 


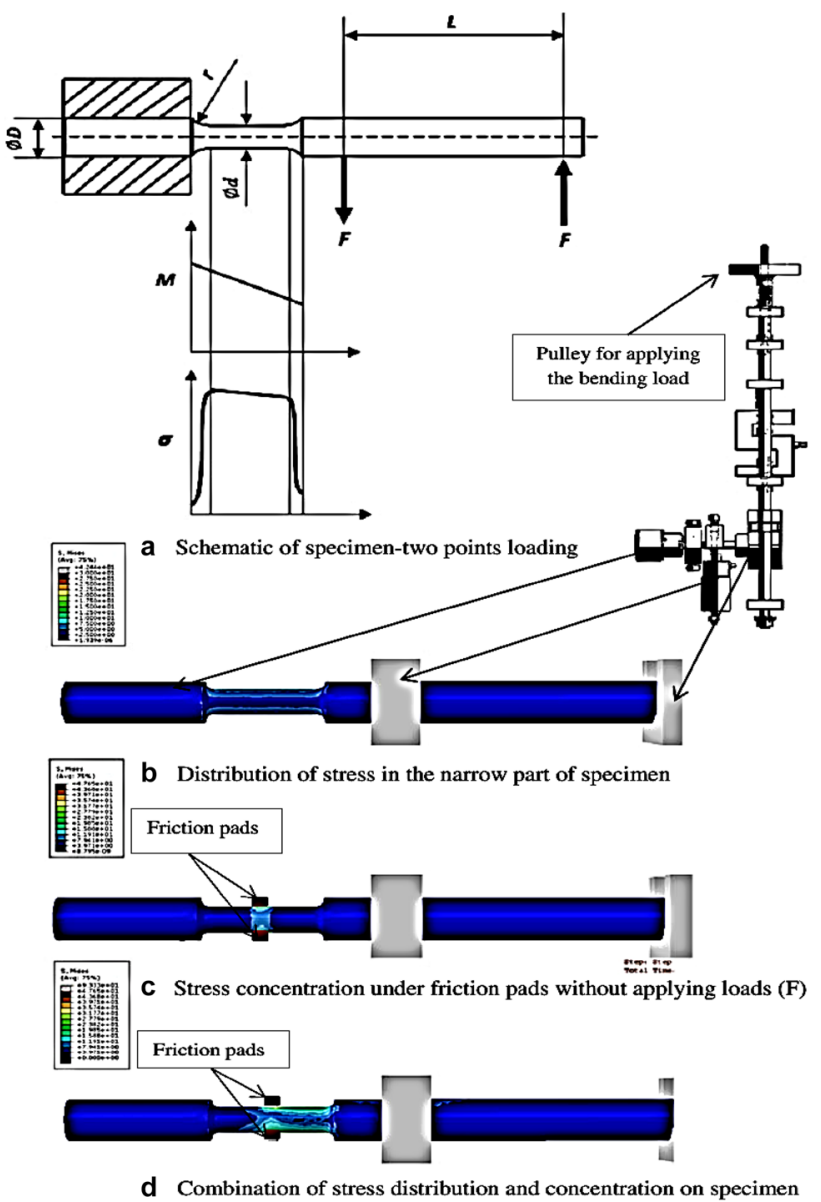

Fig. 14 Sample with dual loading. a Schematic. b Stress along the sample portion. c No load position of friction pad for stress concentration. d Sample under combined stress distribution with concentration [20]. (Permission granted for use through Copyright Clearance Center's RightsLink)

(20) was mounted to assemble wheel axle. Bending load (13) was implied and maintained by high rpm bearing. Maximum $5000 \mathrm{rpm}$ was limited for speed. Velocity was regulated by $\mathrm{AC}$ converter. A geometrically comparative minor scale railway axle is shown in Fig. 20.

\subsubsection{Experimental details [21]}

Here in the research [21], $1 \times 10^{7}$ cycles was marked as the fatigue life that crack would not be initiated before. Two wheels of Chinese fast railroad, 300 and $350 \mathrm{kmph}$, were reenacted. To be specific, revolving speed for the velocity was 1800 and $2100 \mathrm{rpm}$ for the last one. On completion of the tests, the contact portions were divided by wire electro-release. Affected zones were pieces into little samples. These samples were put into ultrasonic cleaner liquid, $\left(\mathrm{CH}_{3}\right)_{2} \mathrm{CO}$ to evacuate the contaminations. An examining electron magnifying lens (SEM) and an optical magnifying instrument were utilized to examine morphologies. The cracks were found on the surface of these samples by SEM.

\section{Discussion}

Each of the rigs has uniqueness in specific fields. Rotary test rig is useful to exert much stress on the fretting zone when complex type is used for railway axle sample. Moore test rig is advantageous in the sense of pure, totally reversed bending without any existence of shearing force. Hinged-loaded rig has advantage of displacement-control as sinusoidal wave loading. Nonetheless, it has three modules having special controlling purpose each. However, Servo-Hydraulic clamped rig is capable of exerting sufficient force by the advantage of hydraulic press. It is also capable to keep cylindrical fretting pad stable in their definite location which is related to slip occurrence. Bar-spring tightened rig is beneficial when it requires both side bending and greater contact of fretting zone with gaseous atmosphere. Shoe-bolt type is almost similar to servo-hydraulic type except limited loading, pad type and vertical position. As a discussed summary, classification of Bending Fretting Fatigue Test Rigs can be shown as in Fig. 21. 
Fig. 15 Shrink-fitted sample on left, test under motion at right [3]. (Permission granted for use through Copyright Clearance Center's RightsLink)
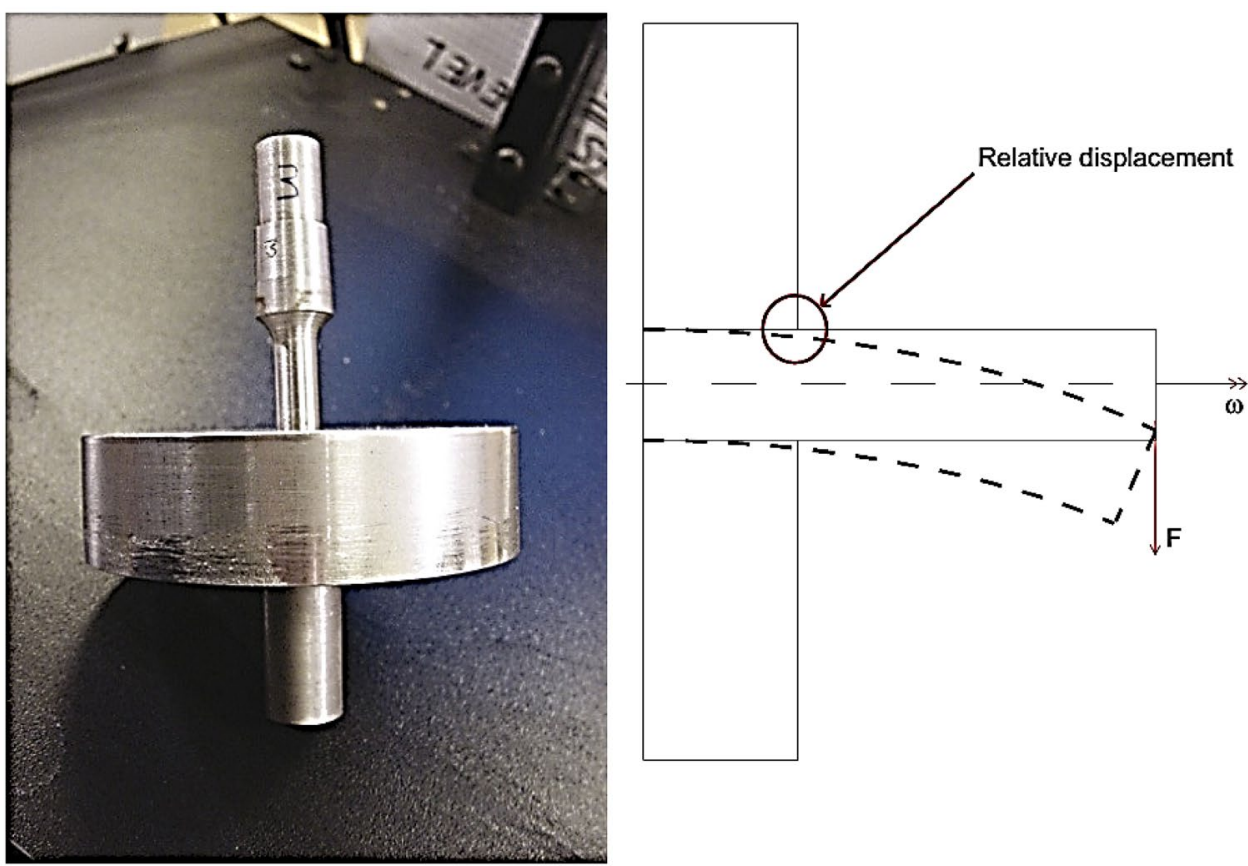

Fig. 16 Ring type load cell (Calibration) [55]. (Permission granted for use through Copyright Clearance Center's RightsLink)

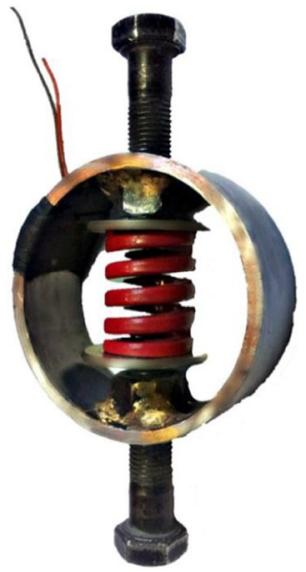

\section{Conclusion}

Different types of bending fretting fatigue test rigs have been described in this article. Depending on the specimen size and shapes, loading-clamping types with direction, full scale i.e., real/in situ geometry and coupon scale geometry i.e. concentrated area of interest, testing setups are being designed in versatile dimensions. Moreover, contact geometry as well as fretting pad shape and size also plays a vital role on the design of bending fretting fatigue test rigs. Data acquisition for load points and stress/strain controlled atmosphere brings complicity to some extents. Discussed articles have been summarized as a gist just to give some hints on the parametric design requirements for upcoming more complex design

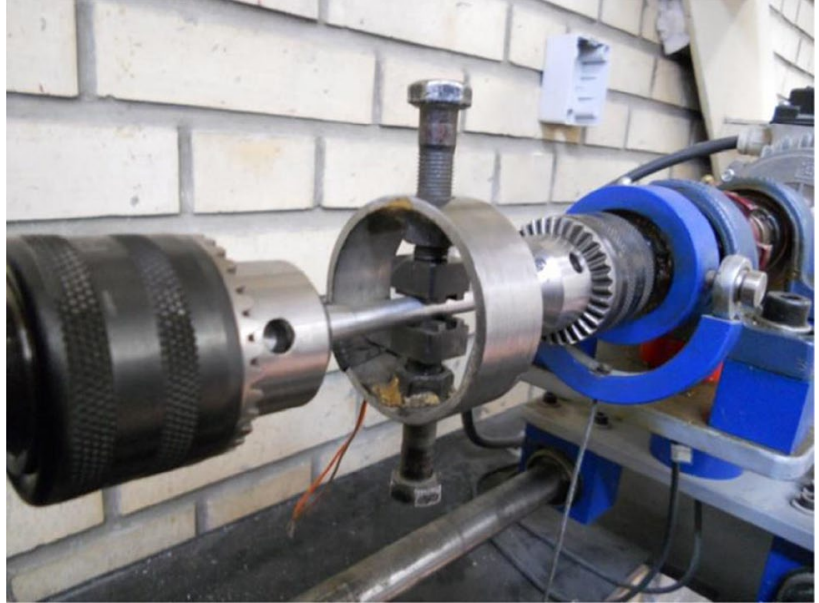

Fig. 17 Testing setup [55]. (Permission granted for use through Copyright Clearance Center's RightsLink)

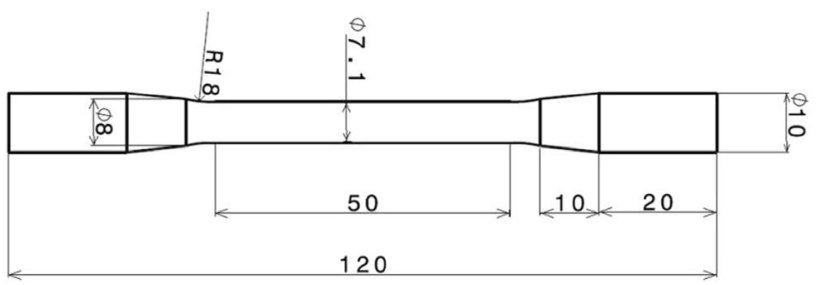

Fig. 18 Geometry of the samples (dimensions are in millimeter) [55]. (Permission granted for use through Copyright Clearance Center's RightsLink) 


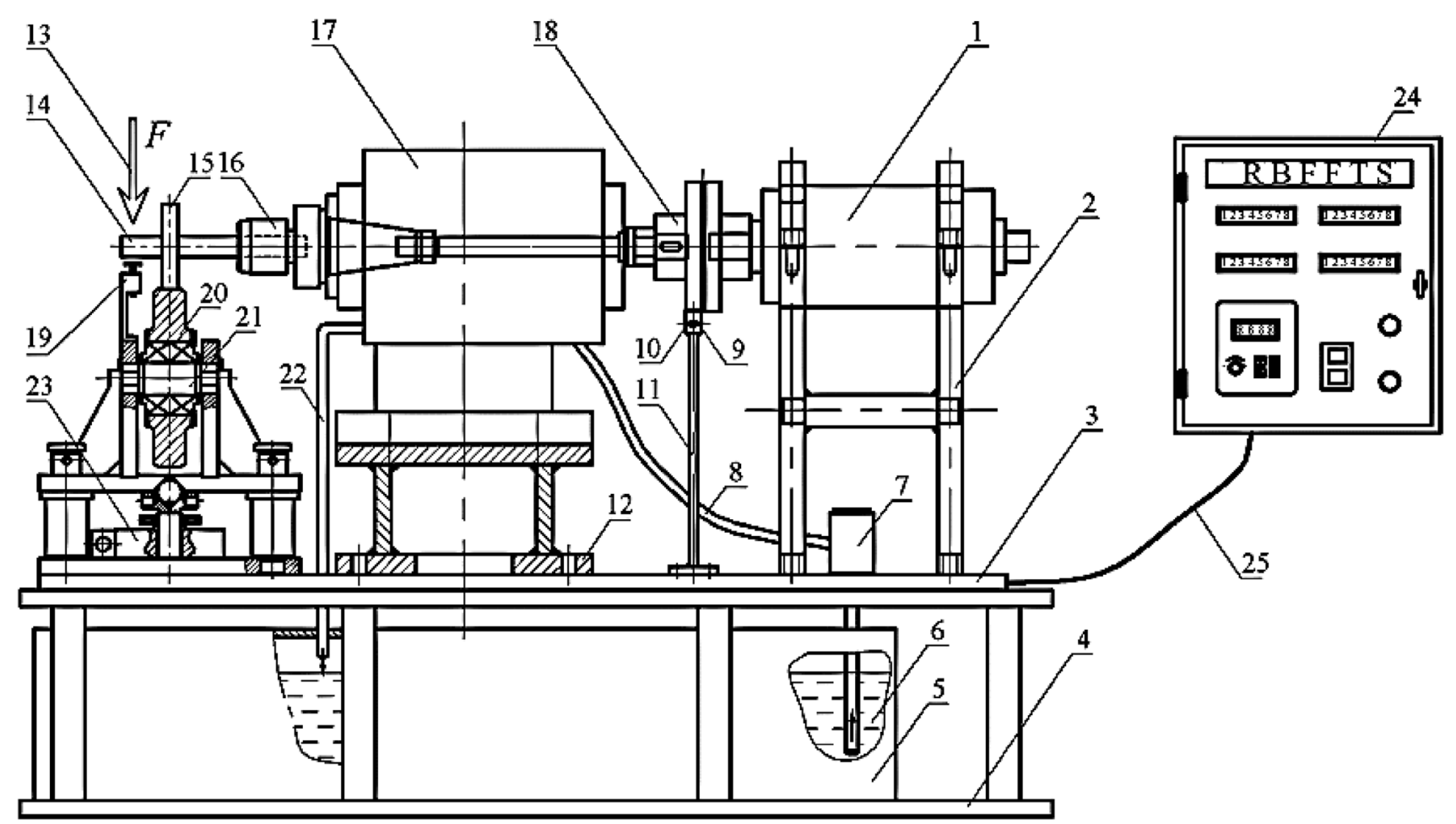

Fig. 19 Rotatory test rig as illustrated in [21]. (Permission granted for use through Copyright Clearance Center's RightsLink)

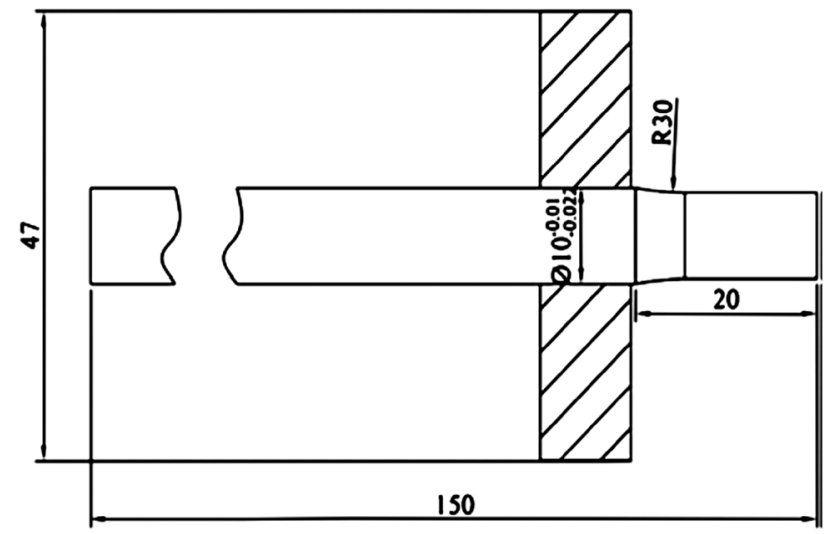

Fig. 20 Dimension of sample (dimensions are in mm) [21]. (Permission granted for use through Copyright Clearance Center's RightsLink) to achieve multi-dimensional results with preciseness. It may be concluded that, each type of existing test rig is regarded noteworthy because of their user/researcher required specifications. Future researchers might utilize any of the presented rigs depending upon the desired testing conditions like slip, loading value, pad type, displacement and other related operating and processing parameters to develop a new universal test rig of fretting fatigue for industrial applications. 


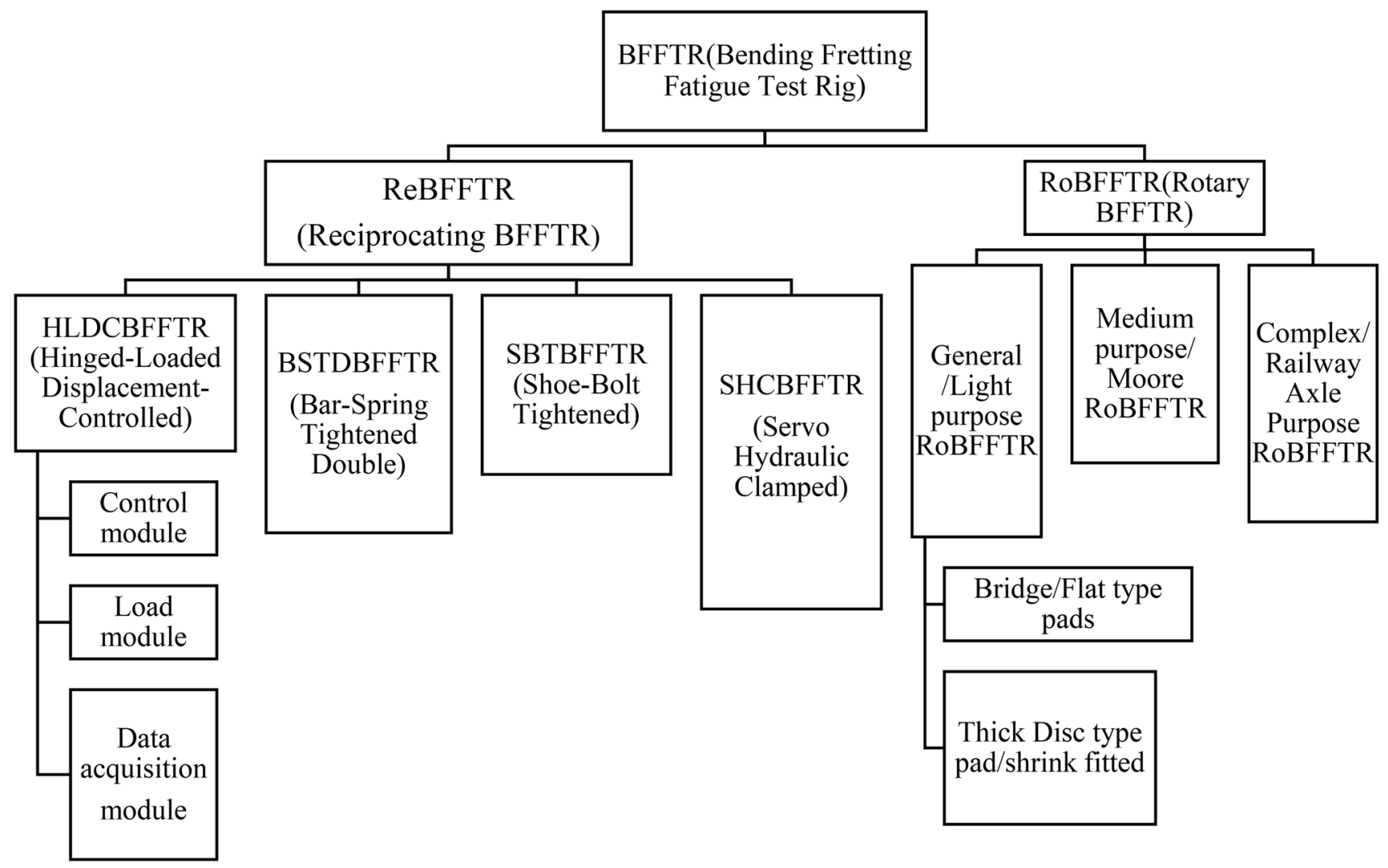

Fig. 21 Classification of bending fretting fatigue test rigs

\section{Compliance with ethical standards}

Conflict of interest The authors declare that they no conflict of interest.

\section{References}

1. Chowdhury MA, Arefin Kowser M, Zobaer Shah QM, Das S (2018) Characteristics and damage mechanisms of bending fretting fatigue of materials. Int J Damage Mech 27(4):453-487. https:// doi.org/10.1177/1056789517693412

2. Greer AL, Rutherford KL, Hutchings IM (2002) Int Mater Rev 47(2):87-112. https://doi.org/10.1179/095066001225001067

3. Gutkin R, Alfredsson B (2008) Growth of fretting fatigue cracks in a shrink-fitted joint subjected to rotating bending. Eng Fail Anal 15(5):582-596

4. Stack MM (2005) Bridging the gap between tribology and corrosion: from wear maps to Pourbaix diagrams. Int Mater Rev 50(1):1-17. https://doi.org/10.1179/174328005X14302

5. Bhushan B (1999) Wear and mechanical characterisation on micro-to picoscales using AFM. Int Mater Rev 44(3):105-117. https://doi.org/10.1179/095066099101528243

6. Hattori T, Kien VT, Yamashita M (2011) Fretting fatigue life estimations based on fretting mechanisms. Tribol Int 44(11):13891393. https://doi.org/10.1016/j.triboint.2010.10.020

7. Hills DA (1994) Mechanics of fretting fatigue. Wear 175(1-2):107-113
8. Ebara R, Fujimura M (2006) Tribol Int 39(10):1181-1186. https:// doi.org/10.1016/j.triboint.2006.02.007

9. Nowell D, Dini D, Hills D (2006) Recent developments in the understanding of fretting fatigue. Eng Fract Mech 73(2):207222. https://doi.org/10.1016/j.engfracmech.2005.01.013

10. Mayama T, Sasaki K, Kuroda M (2008) Quantitative evaluations for strain amplitude dependent organization of dislocation structures due to cyclic plasticity in austenitic stainless steel 316L. Acta Mater 56(12):2735-2743. https://doi.org/10.1016/j. actamat.2008.02.005

11. Yaguchi H (2001) Fatigue-damage evaluation in aluminum heat-transfer tubes by measuring dislocation cell-wall thickness. Mater Sci Eng, A 315(1):189-194. https://doi.org/10.1016/S0921 -5093(01)01156-X

12. Gaudin C, Feaugas X (2004) Cyclic creep process in AISI $316 \mathrm{~L}$ stainless steel in terms of dislocation patterns and internal stresses. Acta Mater 52(10):3097-3110. https://doi. org/10.1016/j.actamat.2004.03.011

13. Hutson A, Sathish S, Nicholas T (2006) Progression of fretting fatigue damage in Ti-6Al-4V. Tribol Int 39(10):1197-1205. https ://doi.org/10.1016/j.triboint.2006.02.009

14. De Pauw J, De Baets $P$, De Waele W (2011) Sustainable Construction and Design 2011 (SCAD). 2011. Ghent University, Laboratory Soete. https://biblio.ugent.be/publication/11674 $88 /$ file/1167506

15. Peng $J$ (2014) On the damage mechanisms of bending fretting fatigue. Tribol Int 76:133-141. https://doi.org/10.1016/j.tribo int.2013.12.018

16. Peng J-F (2013) Study on bending fretting fatigue damages of 7075 aluminum alloy. Tribol Int 59:38-46. https://doi. org/10.1016/j.triboint.2012.06.016 
17. Peng J (2011) An experimental study on bending fretting fatigue characteristics of $316 \mathrm{~L}$ austenitic stainless steel. Tribol Int 44(11):1417-1426. https://doi.org/10.1016/j.tribo int.2010.11.013

18. Kubota M (2011) Mechanism of reduction of fretting fatigue limit caused by hydrogen gas in SUS304 austenitic stainless steel. Tribol Int 44(11):1495-1502. https://doi.org/10.1016/j. triboint.2010.11.004

19. Zalnezhad E, Sarhan AA, Hamdi M (2013) Fretting fatigue life evaluation of multilayer $\mathrm{Cr}-\mathrm{CrN}$-coated Al7075-T6 with higher adhesion strength-fuzzy logic approach. Int J Adv Manuf Technol 69(5-8):1153-1164. https://doi.org/10.1007/s0017 0-013-5093-8

20. Zalnezhad E, Sarhan AA, Jahanshahi P (2014) A new fretting fatigue testing machine design, utilizing rotating-bending principle approach. Int J Adv Manuf Technol 70(9-12):22112219. https://doi.org/10.1007/s00170-013-5457-0

21. Song $C$ (2014) An investigation on rotatory bending fretting fatigue damage of railway axles. Fatigue Fract Eng Mater Struct 37(1):72-84. https://doi.org/10.1111/ffe.12085

22. Majzoobi GH, Abbasi F (2018) An investigation into the effect of normal load frequency on fretting fatigue behavior of Al7075-T6. Tribol Trans 61(3):547-559. https://doi. org/10.1080/10402004.2017.1371366

23. Luke M, Burdack M, Moroz S, Varfolomeev I (2016) Experimental and numerical study on crack initiation under fretting fatigue loading. Int J Fatigue 86:24-33

24. Van Paepegem W, Degrieck J (2001) Experimental set-up for and numerical modelling of bending fatigue experiments on plain woven glass/epoxy composites. Compos Struct 51(1):18. https://doi.org/10.1016/S0263-8223(00)00092-1

25. Waterhouse RB (1992) Fretting fatigue. Int Mater Rev 37(1):77-98

26. Gbur Janet L, Lewandowski John J (2016) Fatigue and fracture of wires and cables for biomedical applications. Int Mater Rev 61(4):231-314. https://doi.org/10.1080/09506608.2016.11523 47

27. Elder JE, Thamburaj R, Patnaik PC (1989) Optimising ion implantation conditions for improving wear, fatigue, and fretting fatigue of Ti-6Ai-4V. Surf Eng 5(1):55-79

28. Liao Y, Marks L (2017) In situ single asperity wear at the nanometre scale. Int Mater Rev 62(2):99-115

29. Hwang B, Kim T, Han SM (2016) Compression and tension bending fatigue behavior of $\mathrm{Ag}$ nanowire network. Extreme Mech Lett 8:266-272

30. Jiménez-Peña $C$ et al (2017) Investigations on the fretting fatigue failure mechanism of bolted joints in high strength steel subjected to different levels of pre-tension. Tribol Int 108:128-140

31. Ma Y et al (2015) The bending fatigue performance of cementstabilized aggregate reinforced with polypropylene filament fiber. Constr Build Mater 83:230-236

32. Mao W et al (2015) A regression and beam theory based approach for fatigue assessment of containership structures including bending and torsion contributions. Mar Struct 41:244-266

33. Gupta $\mathrm{S}$ et al (2015) High compressive pre-strains reduce the bending fatigue life of nitinol wire. J Mech Behav Biomed Mater 44:96-108

34. Beyene AT, Belingardi G (2015) Bending fatigue failure mechanisms of twill fabric E-Glass/Epoxy composite. Compos Struct 122:250-259. https://doi.org/10.1016/j.compstruct.2014.11.067

35. Wentzel $H$, Huang $X$ (2015) Experimental characterization of the bending fatigue strength of threaded fasteners. Int J Fatigue 72:102-108
36. Lin ZX (2016) In situ observation of fracture behavior of canine cortical bone under bending. Mater Sci Eng, C 62:361-367. https://doi.org/10.1016/j.msec.2016.01.061

37. Ma C et al (2016) Microstructures and properties of asymmetrical rolled $7050 \mathrm{Al}$ alloy plate with bending behavior optimization. Mater Sci Eng, A 657:322-330

38. Ahmadi $\mathrm{H}$ (2016) A probability distribution model for SCFs in internally ring-stiffened tubular KT-joints of offshore structures subjected to out-of-plane bending loads. Ocean Eng 116:184-199

39. Li K (2016) Int J Fatigue 85:65-69. https://doi.org/10.1016/j. ijfatigue.2015.12.013

40. Foletti S, Beretta S, Gurer G (2016) Defect acceptability under full-scale fretting fatigue tests for railway axles. Int J Fatigue 86:34-43

41. Huang $L$ et al (2016) Fatigue and fretting of mixed metal selfpiercing riveted joint. Int J Fatigue 83:230-239

42. Komoda R, Kubota M, Furtado J (2015) Int J Hydrogen Energy 40(47):16868-16877. https://doi.org/10.1016/j.ijhyd ene.2014.12.129

43. Gandiolle C, Fouvry S (2016) Stability of critical distance approach to predict fretting fatigue cracking: a " $\ell$ opt-b opt" concept. Int J Fatigue 82:199-210

44. Shi L et al (2016) An investigation of fretting fatigue in a circular arc dovetail assembly. Int J Fatigue 82:226-237

45. Montebello C (2016) Int J Fatigue 82:188-198. https://doi. org/10.1016/j.ijfatigue.2015.02.009

46. Huang Y, Wang Z, Zhou Q (2016) Numerical studies on the surface effects caused by inhomogeneities on torsional fretting. Tribol Int 96:202-216

47. Hu, Z., et al., Effect of plastic deformation on the evolution of wear and local stress fields in fretting. International Journal of Solids and Structures, 2016

48. Hirsch Michael R, Neu Richard W (2016) Temperature-dependent fretting damage of high strength stainless steel sheets. Wear 346:6-14

49. Ghosh Arnab, Wang Weiyi, Sadeghi Farshid (2016) An elasticplastic investigation of third body effects on fretting contact in partial slip. Int J Solids Struct 81:95-109

50. Winkler J, Georgakis CT, Fischer G (2015) Fretting fatigue behavior of high-strength steel monostrands under bending load. Int J Fatigue 70:13-23

51. Kowser MA, Chowdhury MA, Shah QMZ (2017) Effect of loading parameter on fretting fatigue. In: AIP conference proceedings, AIP Publishing. vol 1851, no 1, p 020095

52. Shah QMZ, Chowdhury MA, Kowser MA (2019) Failure mechanism of polytetrafluoroethylene under friction fatigue. J Fail Anal Prev 19(1):245-249

53. Di Franco G et al (2011) Design and use of a fatigue test machine in plane bending for composite samples and bonded joints, vol 2011. InTech, Thousand Oaks

54. Johnson KL (1995) Contact mechanics and the wear of metals. Wear 190(2):162-170

55. Majzoobi GH, Jouneghani FZ, Khademi E (2016) Experimental and numerical studies on the effect of deep rolling on bending fretting fatigue resistance of Al7075. Int J Adv Manuf Technol 82(9-12):2137-2148

Publisher's Note Springer Nature remains neutral with regard to jurisdictional claims in published maps and institutional affiliations. 